Int. J. Electrochem. Sci., 15 (2020) $9796-9810$

International Journal of

ELECTROCHEMICAL

SCIENCE

WWW.electrochemsci.org

\title{
Effect of Different Microstructure on Corrosion Behavior of Magnesium Alloy Sheets
}

\author{
Wen Kang ${ }^{1}$, Feng $L i^{1,2, *}$, Wen Yong Shi ${ }^{3}$, Xue Wen $L i^{1}$ \\ ${ }^{1}$ School of Materials Science and Engineering, Harbin University of Science and Technology, Harbin \\ 150040, P R China; \\ ${ }^{2}$ Key Laboratory of Advanced Manufacturing and Intelligent Technology, Ministry of Education, \\ Harbin University of Science and Technology, Harbin 150080, P R China; \\ ${ }^{3}$ Department of Graduate School, Harbin University of Science and Technology, Harbin 150080, P R \\ China. \\ *E-mail: fli@hrbust.edu.cn
}

doi: $10.20964 / 2020.10 .07$

Received: 10 October 2019 / Accepted: 8 May 2020 / Published: 31 August 2020

\begin{abstract}
AZ31 magnesium alloy sheets with different grain sizes produced by continuous variable cross-section direct extrusion (CVCDE) were rolled at different temperatures. The results show that the combination of CVCDE and hot rolling results in the combination of compressive stress and tensile stress, thus the grain size is greatly refined. When the grains are in a certain size, the magnesium alloy sheet will obtain a better corrosion resistance. Except for this size, too large or too small will make the corrosion resistance decrease. The residual stress inside the magnesium alloy sheet rolled at $350{ }^{\circ} \mathrm{C}$ is relatively large, and it is easy to cause stress corrosion cracking in corrosive medium. Stress corrosion greatly reduces the mechanical properties of magnesium alloys.
\end{abstract}

Keywords: AZ31 magnesium alloy sheet, CVCDE, Rolling, Corrosion resistance

\section{$\underline{\text { FULL TEXT }}$}

(C) 2020 The Authors. Published by ESG (www.electrochemsci.org). This article is an open access article distributed under the terms and conditions of the Creative Commons Attribution license (http://creativecommons.org/licenses/by/4.0/). 